\section{Los habitantes del monte en Puyuhuapi y Cerro Castillo: Prácticas locales en bosques prohibidos y ajenos}

The inhabitants of the monte in Puyuhuapi and Cerro Castillo: local practices in foreign and prohibited forests

\section{Macarena Libuy-Hidalgo*}

\section{Resumen}

En este artículo se analiza el vínculo entre los habitantes locales de Puyuhuapi y Cerro Castillo - XI región de Aysén- con el bosque nativo (monte) en la actualidad. Se describen las diversas prácticas y saberes locales que ligan material y simbólicamente al bosque con las comunidades, dando cuenta de la relación viva que hay entre ambos. Al situar esta relación viva en el contexto actual, vemos que está marcada y tensionada por una serie de políticas

\footnotetext{
Antropóloga Social, Universidad de Chile. Artículo realizado en el marco del Proyecto Fondecyt N1141169. Correo electrónico: libbuy@gmail.com
}

de mercantilización de la naturaleza, propias del capitalismo verde, como lo son: los cambios en la propiedad de la tierra, el turismo asociado a las áreas protegidas, las normativas respecto al uso de los recursos del bosque y las ideas conservacionistas que permean todo lo anterior. Se enfrentan, entonces, distintos modos de concebir la relación humano-monte, dando lugar a una silenciosa disputa por la apropiación material y simbólica del bosque.

Palabras claves: relación naturaleza/cultura, monte (bosque), prácticas locales, mercantilización de la naturaleza, capitalismo verde

\section{Abstract}

This article analyzes the current relationship between the local inhabitants of Puyuhuapi and Cerro Castillo -the $\mathrm{XI}^{\text {th }}$ region of Aysén- with the native forest (monte). It describes the diverse local practices and knowledges that materially and symbolically link the forest with the communities, showing the alive relationship between the two. Putting this relationship in the contemporary context, we see that it is marked and stressed by a series of commodification policies of the nature of green capitalism, such as: changes in land ownership, tourism associated with protected areas, regulations regarding the use of forest resources and conservationist ideas that permeate all the above. Thus, they face different ways of conceiving the human-monte relationship, giving rise to a silent dispute over the material and symbolic appropriation of the forest.

Key words: nature / culture relationship, monte (forest), local practices, commodification of the nature, green capitalism. 


\section{Introducción}

El valor ambiental y la condición periférica o aislada de la región de Aysén funcionan como mercancía desde fines de la dictadura. Esto ha generado una transformación en el modelo clásico de apropiación del espacio por parte de los colonos-campesinos, haciendo emerger, desde 1989, nuevos intereses y políticas de libre mercado ligados a la naturaleza, como el turismo, la conservación y el mercado de tierras (Nuñez et al. 2014). A partir de lo anterior, diversos actores exógenos, tanto públicos como privados, han ido construyendo el "Aysén, Reserva de Vida"1, tierra fértil para cultivar el imaginario de una Patagonia como marca, producto y significante verde: lugar de refugio, paraíso turístico, frontera de la civilización, arquetipo de una naturaleza inmaculada y en reserva (Rodríguez et al. 2014).

En este contexto, la pregunta por los bosques y sus comunidades estará marcada por la visión hegemónica de una naturaleza prístina en la región, que sitúa al monte -como se le llama localmente al bosque- como una mercancía atractiva por su belleza y valor ecológico, como la postal de un paisaje sin humanos, deslumbrante e idealizado².

Sin embargo, al hacer un zoom y, a la vez, romper esa dimensión única que nos entrega esta visión de bosque como postal, podemos profundizar en las tramas microscópicas, advirtiendo que

Eslogan que adopta el Gobierno Regional (GORE) en "Estrategia Regional de Desarrollo. Coyhaique 2009".

Esta visión tiene su correlato en el movimiento conservacionista a nivel global y el consecuente aumento de los espacios naturales o áreas protegidas a partir de los años 70' del siglo pasado (Santamarina 2009). Esto ha levantado toda un área de interés dentro de la antropología y en especial en la etnografía de los parques naturales y sus consecuencias geopolíticas y ecológicas. en el bosque no hay solo coihues (Nothofagus dombeyi) o lengas (Nothofagus pumilio) gigantes, sino también cientos de helechos, flores y enredaderas. Del mismo modo, en el ámbito social, nos encontraremos con un bosque lleno de historias locales y de saberes, intervenido y utilizado durante cientos de años.

Incluso si alejamos la imagen llevándola a un plano más macro, veremos a ese mismo bosque inserto en un tejido de complejas relaciones con lo global, disputándose históricamente entre diversos actores, intereses y relaciones de poder, transformándose y cambiando constantemente su valor.

En este artículo queremos hacer ese ejercicio, de entender al monte ya no como una imagen neutra, estática o meramente estética, sino que, en interrelación y diálogo con distintos grupos humanos, que tienen, a su vez, distintas maneras de leer y actuar en relación a su medioambiente; $y$, por tanto, un monte sobre el que recaen percepciones y prácticas diversas que entran en conflicto o choque. En esa línea empezaremos a mirar y a bosquejar este monte como un espacio politizado que, al igual que todo espacio natural, nos permite vislumbrar las relaciones de dominación que existen tras su conformación histórica, donde afloran disputas materiales (propiedad, recursos y usos) y simbólicas (valores, identidad) entre los distintos grupos que conviven en él (Santamarina 2009).

Este acercamiento y desdoblamiento de la imagen del monte, cuyo objetivo central es caracterizar y comprender la relación de los habitantes locales con el bosque nativo en el contexto neoliberal, nace a partir de un trabajo de campo etnográfico realizado en Puyuhuapi y 
Cerro Castillo durante tres meses el año $2015^{3}$. Esta etnografía nos permitió entrever la viva relación que mantienen los habitantes locales con el monte, el que es fundamental para sus economías de subsistencia y, también, fuente de sentido, símbolos y afectividad. A la vez, pudimos advertir cómo este vínculo se ve atravesado por lianas conflictivas en la actualidad, que son propias del contexto neoliberal y que instalan una serie de dificultades, tensiones y transformaciones.

\section{Enfoque teórico}

Esta investigación se enmarca en los enfoques teóricos de la ecología simbólica y la ecología política, desde los que vamos a entender, en primer lugar, la díada naturaleza/cultura no como dicotomía, sino al medio ambiente y sus determinantes sobre la vida social en una relación dialéctica con la creatividad que cada sociedad despliega en la aprehensión y ordenamiento de su medio (Descola 2011). En esa línea, la ecología simbólica dentro de la antropología pone en evidencia que existen diversos modos de edificar las relaciones ser humano/naturaleza, lo que nos va a permitir sacar a la luz las prácticas, instituciones y discursos que condicionan nuestra percepción del medio (Santamarina 2008). Estas distintas nociones sobre el medioambiente implican procesos de negociación y conflictos sobre su significado, lo que nos hace entrar indefectiblemente en el ámbito político.

\footnotetext{
La investigación completa "Bosquejos del Monte. Ensamblajes entre el bosque nativo y los habitantes locales de Puyuhuapi y Cerro Castillo en el contexto neoliberal" está disponible en el sitio web www.tesis.uchile.cl
}

La ecología política viene a nutrir nuestro análisis antropológico al dar cuenta cómo el acceso, los beneficiosyloscostos delosrecursos naturales están mediados por relaciones desiguales de poder (Ulloa 2001). Su campo de estudio, como indica Martínez-Alier (2014), son los conflictos ecológicos distributivos, entendiendo la distribución ecológica como los patrones sociales, espaciales y temporales de acceso a los beneficios que entregan los recursos naturales y a los servicios que proporciona el medioambiente, como un sistema de soporte de vida. Los determinantes de la distribución ecológica son, por una parte, aspectos naturales como el clima, la topografía, las Iluvias, la calidad del suelo, entre otros; y también aspectos sociales, culturales, económicos, políticos y tecnológicos.

De este modo, la ecología política pone el foco en las relaciones que las sociedades humanas mantienen con su medio ambiente, utilizando conceptos de economía política para analizar las relaciones estructurales de poder entre esas sociedades, y las interacciones dinámicas y conflictivas provocadas por el choque de los distintos modos de adaptación ecológica (Elliot 2006). Sin embargo, su análisis no se agota ni debe agotarse ahí, pues como señala Leff:

\footnotetext{
los conflictos socioambientales se expresan como controversias derivadas no sólo de la apropiación material de la naturaleza, sino de los significados diversos -y a menudo antagónicos- asignados a ella, donde los valores éticos, políticos y culturales desbordan el campo de la economía política (2014: 177).
}

Este enfoque es relevante y necesario en el quehacer antropológico pues "se forja en el ámbito de la otredad" (Leff 2014:183), en el (des)encuentro de modos diferenciados de ser, valorar, percibir y accionar en los territorios. 


\section{Metodología}

Para esta investigación se seleccionó el enfoque teórico-metodológico de la etnografía interpretativa, realizándose un trabajo de campo que consistió en tres períodos de terreno de un mes de duración cada uno, durante el año 2015. $\mathrm{Se}$ llevaron a cabo entrevistas semiestructuradas, recorridos guiados y observación participante y pasiva. Todas las técnicas fueron aplicadas con el consentimiento informado de los actores locales que participaron. El registro de los datos se realizó mediante anotaciones en el cuaderno de campo y en grabaciones, posteriormente transcritas y analizadas.

El método etnográfico fue relevante dentro de nuestro enfoque teórico-metodológico, ya que nos permitió explicitar las bases latentes de los conflictos y visibilizar a los grupos marginados. En ese sentido, el uso de una metodología etnográfica es un aporte significativo de la antropología a la ecología política (Elliot 2006). Esto responde también a nuestro interés de desarrollar una perspectiva etnográfica que acentúe tanto lo significativo como lo material, en concordancia con los análisis de la ecología política antropológica, que permiten un acercamiento a las construcciones culturales y ambientales, los conflictos, las luchas y los consensos, tanto sobre los significados, como sobre las prácticas ambientales (Ulloa 2001).

\section{Caracterización de las localidades}

Puyuhuapi y Cerro Castillo son dos localidades de Aysén, la primera de ellas se encuentra en el extremo de un fiordo de origen glacial que lleva el mismo nombre en la zona norte de la región y, la segunda, en la cuenca del Río lbáñez, en el sector oriental trasandino al límite con Argentina. Según el último censo válido, en cada localidad, vivirían cerca de 550 personas ${ }^{4}$.

Imagen 1. Localización Puyuhuapi y Cerro Castillo

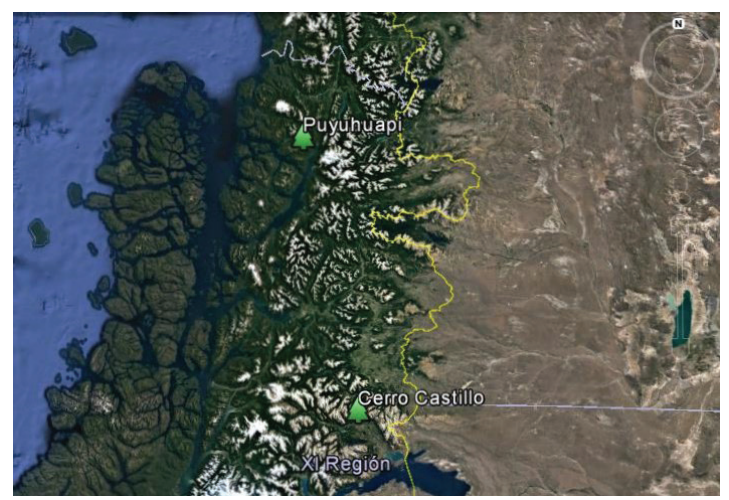

Fuente: Google Earth.

En ambas localidades existen sectores semirurales, la Villa Cerro Castillo y el pueblo de Puyuhuapi, donde se concentra parte importante de la población, y distintas áreas de campos circundantes en donde, hasta hace unos años, se repartían la mayoría de sus habitantes y donde aún viven algunos campesinos.

Las primeras personas en poblar el territorio que hoy se conoce como Cerro Castillo fueron familias huilliche provenientes de Osorno, quienes ingresaron a la región en los primeros años del siglo XX (Martinic 2005). El modo de poblamiento de Cerro Castillo, en el cual los colonos llegaron a habitar y trabajar los campos de forma autónoma, hizo que posteriormente muchos de ellos pudiesen solicitar sus títulos

INE. (2002). CENSO 2002. Volumen I. Resultados Población, País y Región. 
de propiedad y conservar sus campos o los de sus padres hasta el día de hoy.

Por otra parte, la localidad de Puyuhuapi comienza a ser habitada de forma permanente producto de la colonización que realizó un grupo de alemanes, quienes llegaron al fiordo por primera vez en 1933, trayendo a trabajadores chilotes de Queilen, Chuit, Cailín y Chonchi (Ludwig 2013). De esa manera se formó la villa, compuesta en su mayoría por familias de origen chilote, junto a otros trabajadores que fueron llegando desde la zona sur del país (Ludwig 2013). El modo en el que se estableció la población original de Puyuhuapi, marcada por la relación de subordinación que mantenían los chilotes con los colonos alemanes, hizo que la mayoría de ellos no pudiesen ser propietarios de campos y permanezcan hoy en la villa formada por terrenos que donaron los alemanes.

Reconocer el poblamiento de ambas localidades nos permite comprender la estructura social y económica de sus pueblos, así como las relaciones de dominación presentes en su historia. Como veremos, esto tendrá implicancias directas en la forma que toma el vínculo de los habitantes con el monte.

\section{La vida humana en la Selva y la Montaña Colgá}

Los bosques de Puyuhuapi y Cerro Castillo son muy distintos entre sí, tratándose en el caso del primero, del tipo forestal siempreverde, el que es nombrado localmente como Selva por su alta humedad y diversidad de especies. En el caso de Cerro Castillo se trata del tipo forestal lenga, con algunos sectores de bosques de ñire (Nothofagus antárctica), los que son en general mucho más secos. Este último tipo de bosque se denomina localmente Montaña Colgá, pues crece vegetación sólo desde un par de metros hacia arriba, por lo que "uno cabe por abajo" (Raúl, Puyuhuapi5).

En Puyuhuapi y Cerro Castillo el monte se cuela en la vida cotidiana humana, apareciendo en distintas actividades en donde cumple un rol fundamental, brindando las materias primas básicas para la reproducción de sus comunidades.

En términos concretos, podemos conocer la relación bosque-habitantes locales a partir de los usos que hacen estos últimos del monte o de algunos de sus recursos: tanto en las prácticas vinculadas al bosque propiamente tales, como en las representaciones sociales que dotan de sentido esas prácticas y que incluyen valoraciones, saberes, normas e ideas. Los principales usos identificados fueron: Leña, madera, ganadería y productos forestales no madereros (PFNM).

\subsection{Leña}

La obtención y uso de la leña es una de estas prácticas, quizás la más significativa y recurrente. La importancia de este recurso radica en ser la principal fuente de energía usada en la calefacción, en la cocción de alimentos y para calentar permanentemente el agua de las tradicionales rondas de mate. El fuego tiene el poder de congregar en torno a él, generando un espacio donde transcurre gran parte de la vida familiar y social. Obtener leña para el consumo

A cada uno de los/as informantes se le nombra con un seudónimo en este artículo, con la finalidad de mantener su anonimato, previamente acordado mediante la firma de consentimientos informados. 
familiar, ya sea comprándola o sacándola directamente del monte, es una tarea cotidiana imprescindible: "Llueve, truene o caigan piedras, igual hay que salir a la leña" (Raúl, Puyuhuapi), e involucra una serie de conocimientos locales respecto a las características de cada especie y sus propiedades para arder, así como también en cuanto al proceso de obtención de este recurso.

\subsection{Ganadería}

Por las extensas superficies de monte transitan vacas y ovejas, por lo que otra importante actividad desarrollada entre árboles, es la ganadería. Para esta actividad se hace necesaria la "apertura", "despeje" o "limpia" de ciertos "paños" (pedazos) de bosque ${ }^{6}$, tanto para la crianza de los animales, como para la producción de forraje. Esta combinación bosque-animales, que otrora se encontraba totalmente naturalizada dentro de la región, hoy sufre un cuestionamiento por parte de diversos actores, tanto por la tala o quema de árboles que implica, como por la presencia misma del ganado en el monte:

Los animales son el daño, porque el animal usa al árbol como forraje (...) De acuerdo a la ley los animales no deben estar en el bosque, pero en general en esta región, por 3 millones de ha. de bosque que hay, en más de 1 millón de ha. de bosque están metidos los animales (Asesor Técnico del Depto. de Fomento Forestal CONAF XI Región).

La relación de causa-efecto entre el ganado y el daño ambiental del bosque no existe en los campesinos, para quienes la ganadería es una importante fuente de ingresos, y el bosque el

Pues recordemos que los bosques nativos ocupan el 40,4\% de la superficie total de la región (INFOR 2012), es decir, cerca de 4.800.000 hectáreas. medio natural en el que humanos y animales están insertos, por lo que no se concibe un campo (bosque) sin animales, ni animales fuera del campo (bosque).

\subsection{Madera y construcción}

El labrado de madera con hacha o motosierra (o en algunos pocos casos en aserraderos), así como la construcción de viviendas, muebles, ranchos, establos, galpones, entre otros; y su utilización también para la fabricación de postes, cercos y varillas, son una práctica generalizada, regular y especializada entre los habitantes del lugar. El trabajo con madera implica una serie de saberes, por ejemplo, cómo seleccionar un "trozo" y cuándo voltearlo:

En junio se voltea. Ahí no hay hojas en los árboles, solo hay brotes, entonces se deja el trozo tirado hasta octubre cuando le van saliendo hojas. Esas hojas que van naciendo toman de agua la savia que queda en el palo circulando, hasta que se acaba y se seca la hoja. Ahí entonces yo sé que el árbol está muerto, y esa madera no se va a tirar (no se va a enchuecar) y no se va a partir (Mario, Cerro Castillo).

\subsection{Productos forestales no madereros}

Dentro de los PFNM encontramos principalmente el consumo familiar y/o venta de hongos, plantas medicinales y frutos; y la producción de artesanías con especies del monte. Nombraremos solo algunas de estas prácticas.

En cuanto a los hongos, en el caso de Cerro Castillo destaca la recolección de murilla (Morchella conica) para la venta. En Puyuhuapi existe un amplio conocimiento de los hongos presentes en el bosque (Oreja de palo (Ganoderma australe), Gargal (Grifola gargal) entre otros), pero muy bajo consumo de éstos en la actualidad. 
En relación a la recolección de especies vegetales para su consumo como alimento o medicina, destacamos en Puyuhuapi el consumo de nalcas (Gunnera tinctoria) y de frutos de árboles y arbustos nativos como el avellano (Gevuina avellana), el arrayán (Luma apiculata), la chaura (Pernettya mucronata), el calafate (Berberis microphylla), el cauchao (fruto de Amomyrtus luma), maqui (aristotelia chilensis), la picha-picha (Myrceugenia planipes) y el michay (Berberis darwinii).

Respecto a los usos medicinales, existe un amplio conocimiento de las propiedades curativas de yerbas, arbustos y árboles del monte, lo que constituye toda una "medicina de los yuyos" (Susana, Cerro Castillo). Para ejemplificar destacamos en Cerro Castillo a la paramela (Adesmia emarginata), planta que ayuda a mantener la buena salud de la próstata y en las mujeres sirve "para los dolores y el frío en la matriz" (Susana, Cerro Castillo), para lo que también puede usarse en vaporizaciones, cuidando de utilizar la rama verde. La paramela, que "sale por las costas de los ríos y esteros" (Pedro, Cerro Castillo), es además muy buena para la contención urinaria y para el frío.

Existen incluso algunos usos rituales, entre los que destacamos en Puyuhuapi al chaumán (Raukaua laetevirens), árbol nativo al que se le asocian poderes sobrenaturales y propiedades curativas, como nos señalaron distintas personas: "Se usa para el susto, se mezcla con pata de león y toronjil" (Flor, Puyuhuapi); "El chaumán sirve para pegarle a las personas y a las lienzas cuando están maleadas para pescar" (Bertina, Puyuhuapi).

\footnotetext{
"Yuyos" es el término local utilizado para referir a las yerbas.
}

Por último, se realizan artesanías con diversos productos del bosque, dentro de las que destacan las tinturas vegetales, para las que se utilizan especies como la quiaca (Caldcluvia paniculata), el calafate (Berberis microphylla), la barba de palo (Tillandsia usneoides), y el canelo (Drimys winteri); y la cestería principalmente en base a manila (Phormium tenax), junquillo (Juncus procerus), y antiguamente boqui (Boquila trifoliolata).

Todo lo anterior nos permite ir bosquejando la relación viva que existe entre la población local y el bosque nativo, relación basada en un vínculo concreto y cotidiano, que se materializa en cada uno de estos usos, en donde la cultura aparece llena de monte y el monte, lleno de cultura.

En esta continuidad humano-monte, el bosque no se mira ni hacia arriba ni hacia abajo, por tanto, no se le valora de una forma asimétrica, idealista, o que vaya más allá de un vínculo directo. Lo anterior es por completo opuesto a lo que se puede observar en los nuevos actores, relaciones y políticas que llegan y permean la comunidad local y al bosque en el contexto neoliberal. Estos nuevos actores sacan al bosque y a sus componentes del espacio que comparte con la cultura, para llevarlo al circuito mercantil del capitalismo verde, en donde pasa a ser una mercancía atractiva a los ojos de extranjeros y externos, como pasaremos a ver a continuación.

\section{El monte en el contexto neoliberal}

Agudizando nuestra observación del paisaje boscoso-humano de Puyuhuapi y Cerro Castillo, pasaremos a revisar el contexto y las condiciones actuales bajo las que los habitantes 
locales realizan sus prácticas del bosque. El primer elemento que aparece tensionando esta relación es la distribución de la propiedad de la tierra, desde donde se obtienen estos recursos o en la que se realizan las prácticas.

\subsection{Propiedad de la tierra}

En la actualidad, la mayoría de las prácticas del bosque en Puyuhuapi y Cerro Castillo son realizadas por los campesinos en propiedades ajenas. Las personas que pudimos conocer durante el trabajo de campo etnográfico, presentan distintas realidades en cuanto a la propiedad de la tierra, sin embargo, en su mayoría no tienen campo.

Lo anterior se da con más fuerza en el caso de Puyuhuapi, lo que se explica si recordamos que ellos o sus familias llegaron al fiordo a trabajar apatronados cuando recién comenzaba la colonización de la región y nunca solicitaron ni compraron campo:

Mis padres venían de Chonchi, no pidieron tierra al Estado porque para eso había que tener trabajo, animales, dinero, y el trabajo en Puyuhuapi estaba muy malo (Raúl, Puyuhuapi).

Una excepción es Carlos, el único local propietario de campo al que pudimos conocer en profundidad dentro de Puyuhuapi. Carlos recibió por parte de su ex patrón Otto Uebel, 60 ha. de campo por sus años de trabajo. Sin embargo, este "regalo" nunca se formalizó más allá de las palabras, y hoy este informante se encuentra en problemas, pues el sitio en el que ha vivido y trabajado toda su vida está siendo reclamado por los nuevos compradores: una familia de empresarios chilenos.

En el caso de Cerro Castillo, advertimos un mayor número de propietarios, pues como sabemos, esta localidad fue colonizada por campesinos de origen huilliche que llegaron a asentarse de manera independiente, por lo que la mayoría de los actuales habitantes de Cerro Castillo son descendientes de esos primeros colonos y mantienen aún sus campos.

El bajo número de habitantes que en ambas localidades interviene el bosque en su propia tierra está en directa relación con las numerosas ventas de propiedades a externos. Lo anterior, en respuesta a un mercado de tierras regional que se ha acelerado en las últimas décadas, atrayendo a un amplio número de compradores nacionales y extranjeros (Nuñez et al. 2014).

Parte importante de las opiniones de los locales respecto a las nuevas personas que han ido comprando, dan cuenta de una tensión y disputa permanente, ligada fuertemente a la idea de que los externos le quitan el acceso al bosque, cercando y poniendo cuidadores en el perímetro. Lo anterior nos habla de una prohibición que no es sólo tanteable u objetivable en un candado o en un cerco, sino de todo un imaginario entre los habitantes, de que no se puede ir al monte o utilizarlo, pues está prohibido:

Han comprado los que son empresarios en Las Ardillas y después han cerrado, no dejan entrar a uno mismo que es de acá. Yo antes salía, por decir, a la orilla del lago a pescar. Antes teníamos otros conocidos que cuidaban los campos, y compraron otros y pusieron a otras personas y ellos no dejan ir para allá. Antes íbamos a pescar, a hacer cualquier cosa (...) ¿y quiénes compraron esas tierras? (...) los caballeros Pucci (Pedro, Cerro Castillo).

Otra idea reiterada en relación al tema de los extranjeros, es que ellos compran la tierra, pero no la trabajan. Se considera que los nuevos compradores tienen las tierras para conservar, para pasear un par de días al año, para hacer negocios o especulación financiera: 
No les dan ninguna utilidad, compran como una inversión, llegan, hacen negocios, después llegan otros con más plata y les venden los campos, y no los usan para nada (Carlos, Puyuhuapi).

Esto se debería a que ellos vienen con otras ideas e intereses:

Los gringos vienen porque es la "Reserva de Vida"” (Andrés, Cerro Castillo); Ellos quieren comprar para que esta Patagonia siga intacta, para llegar, entrar a un bosque y que no esté intervenido por la gente, por la mano del hombre (...) Son casi todos ecologistas, no botan ni un palo (Mario, Cerro Castillo).

Es relevante también considerar el caso de los cuidadores de tierra de extranjeros, ya que, si bien no son propietarios de campo, mantienen cierta cercanía con los dueños, pudiendo tener cultivos y animales dentro de sus predios y obtener todo tipo de recursos del bosque. Además, tienen una concepción de los propietarios como gentes generosas:

Cuando llegó la gringa mi vida cambió (...) pagan mejor que en cualquier pega; los gringos viven en su mundo, si ellos pueden colaborar con la gente, lo hacen... la gringa es súper humilde (Mario, Cerro Castillo).

Estas personas, en general, sostienen malas relaciones con los vecinos, incluso en una de las localidades, se han producido reiterados episodios de violencia (golpizas, asesinato de perros, y variadas riñas con intervención de carabineros), cuando el cuidador ha sorprendido a habitantes locales ingresando al monte, ya sea para buscar leña, o dejar a algún animal. Esto, de alguna manera, ilustra cómo la restructuración de la propiedad de la tierra modifica no solo la vida cotidiana y material de los habitantes locales, sino también las relaciones comunitarias entre los vecinos del lugar, muchas veces enemistados ante las nuevas circunstancias.
Junto a los cambios en la propiedad de la tierra y sus consecuencias dentro de los territorios, el turismo, de la mano del paradigma conservacionista, constituye un nuevo elemento relevante a la hora de caracterizar y comprender las particularidades que la relación de los habitantes locales con el monte toma en el contexto neoliberal.

\subsection{Turismo, ecologismo y capitalismo}

Los discursos asociados a la naturaleza en Aysén están dirigidos permanentemente a exaltar las características de sus ecosistemas y su biodiversidad, como lo ejemplifica esta cita del SERNATUR:

Es un territorio rico en naturaleza y aventura en el extremo sur de Chile, con una amplia diversidad de paisajes y climas. Es la región más rica en aguas dulces de Chile, y una de las más puras del planeta 8 .

La atención y exaltación que concentra lo natural dentro de la región, junto al paradigma ecologista del "culto a lo silvestre" que lo sustenta, se expresa también en las más de 5 millones de hectáreas de parques nacionales, lo que convierte a Aysén en el mayor sistema de áreas silvestres protegidas del país. A esto podemos sumarle el característico eslogan "Aysén, Reserva de Vida", el que desde sus

SERNATUR 2015: Región de Aysén. En http://www.sernatur.cl/ region-de-aysen/?lcp_page $0=3 \# I c p \_i n s t a n c e \_0$. (consultado en Agosto 2015).

9 Entendemos las ideas ecologistas de esta región como un tipo de ecologismo llamado "culto a lo silvestre", en base a la descripción de Martínez-Alier (2014: 21), para quien sería: "una defensa de la naturaleza inmaculada, del amor a los bosques primarios y a los ríos prístinos: el "culto a lo silvestre" que fue representado hace ya más de cien años por John Muir y el Sierra Club de EEEUU". Esta corriente del ecologismo busca conservar lo que queda de los espacios prístinos, sin cuestionar el modelo económico, pues no nace de intereses materiales sino de una valoración romántica de los bellos paisajes. 
orígenes en los años 80', empieza a ser utilizado de distintas maneras: en políticas de gobierno, tiendas, marcas y campañas turísticas ${ }^{10}$, siendo adoptado incluso por el Gobierno Regional:

La calidad medioambiental de la región de Aysén constituye una ventaja competitiva que debe ser resguardada para sustentar la producción de bienes y servicios de todo tipo, pero en especial, de aquellos vinculados a la industria turística de intereses especiales. Consecuentemente con ello, la región ha adoptado el slogan Aysén Reserva de vida (GORE, 2009: 15).

De este modo se genera una alianza entre los ecologistas, el Estado y el mercado, quienes se ven beneficiados de este "Aysén, Reserva de Vida". Esta característica es la que logra atraer a turistas extranjeros y nacionales, y que ha hecho de Aysén el corazón de un fuerte mercado de tierras ${ }^{11}$.

El contexto regional repercute y se refleja en las localidades de estudio, sobre todo si consideramos que ambas están circundadas por áreas protegidas: en el caso de Cerro Castillo por la Reserva Nacional Cerro Castillo, y en Puyuhuapi por el Parque Nacional Queulat. Estas áreas protegidas congregan anualmente a cientos de turistas, lo que ha generado que muchos habitantes locales desarrollen nuevos

10 Estos datos se encuentran detallados en las libretas "Foros taller Aysén Reserva de Vida 1997" de CODEFF (2005), en la Biblioteca Regional de Aysén, ubicada en la ciudad de Coyhaique.

11 Nuñez, Aliste y Bello (2016), dan cuenta de estas dinámicas en las comunas de O'Higgins y Tortel, mostrando cómo en el período 1989-2015, propietarios tales como Aguilar, Gómez, Fierro, Cruces, López, Vargas, entre otros, se ven reemplazados por nombres como "Las Margaritas S.A, Ganadera y Forestal Hacienda El León S. A., ENDESA S.A, Sociedad Agrícola Caiquén, Inversiones Santa Pamela, Waters of Patagonia, Inversiones Patagonia, entre otras" (Nuñez et al. 2016: 9-10). Del mismo modo, Romero (2017) da cuenta de esta transformación en el Valle Exploradores, en donde empresas como "Inmobiliaria e Inversiones Godeliber Limitada", "Inversiones Lados Sur Limitada", "Inversiones Integradas Limitada", "Smith y Jonhson IL", "El Agua S.A" y "Campos Bahía Exploradores S.A", han ido ocupando el lugar de los colonos o pobladores tradicionales desde 1989 hasta la actualidad. negocios, como dar alojamiento, ofrecer almuerzos y vender artesanías o provisiones; y también que empresarios externos instalen lujosos centros turísticos, como hoteles, lodges u ofrezcan servicios de turismo-aventura.

Las relaciones entre la población local y las áreas protegidas son bastante distanciadas. Los parques o reservas nacionales aparecen en la opinión de los locales sólo cuando se habla de las prohibiciones o nuevas normativas respecto al uso de los bosques y, además, pudimos constatar que no visitan los parques ni tampoco consumen servicios turísticos. Sin embargo, los lugares en donde estos centros turísticos se asientan, forman parte de un pasado común para la población local, ya que se trata de tierras que eran de familiares o conocidos, que eran parte de sus circuitos, o bien lugares a los que acudían en busca de algún tipo de recurso. Es por esto que no son concebidos como lugares donde ir a pasear, pues el turistear no es una actividad que forme parte de sus vidas ni de sus expectativas, en tanto la delimitación y normatividad de un espacio natural, con circuitos establecidos, actividades y atractivos prefijados por parámetros turísticos y comerciales, además del costo monetario que esto significa, son ajenos a sus valoraciones y usos culturales del entorno, y también ajenos a sus posibilidades adquisitivas.

Es interesante destacar a modo de ejemplo el caso de las termas en Puyuhuapi, donde el sector que actualmente se conoce como "Termas Puyuhuapi" era habitado y concurrido por los habitantes de la zona hasta que fue comprado por empresarios que empezaron a cobrar cifras exorbitantes para entrar ${ }^{12}$. Ese

En el momento en que se llevó a cabo el trabajo de campo, la entrada a estas termas bordeaba los $\$ 100.000$ por persona diarios. 
sector constituye un espacio importante que está en la memoria colectiva de la comunidad, ya que en sus alrededores vivían familias completas: "Iba a las termas cuando chica porque quedaban ahí mismo donde vivía (...) cocinábamos los choritos en el agua caliente" (Flor, Puyuhuapi); “Íbamos a las termas cuando eran naturales (Bertina, Puyuhuapi)".

Ese "cuando eran naturales" hace referencia al tiempo en el que no estaban en su formato comercial y lujoso actual, que les hace "perder naturalidad"; pues para los empresarios el marketing consiste justamente en resaltar "lo natural" de estos espacios, y que para los habitantes locales, por el contrario, representa la pérdida de su naturalidad.

Lo anterior es un ejemplo claro de lo que sucede en poblaciones rurales rodeadas de naturaleza, en consonancia con las directrices de la economía neoliberal y la mercantilización de lo natural mediante el turismo, generando que los habitantes locales transiten desde un vivir "en" la naturaleza a un vivir "de" la naturaleza: "de su uso, de su transformación, a vivir de los que vienen temporalmente a 'vivir en la naturaleza'" (Frigolé 2006: 26 Cit. en Santamarina 2009: 317). De este modo, se produce una apropiación urbana del paisaje rural, en donde los beneficios económicos no recaen precisamente sobre los locales, sino que, por el contrario, éstos son marginados.

Se genera entonces una interesante tensión, pues si bien los modelos locales de uso, apropiación y percepción del territorio son en su mayoría contrarios a los modelos mercantiles actuales, éstos últimos son en la actualidad una importante fuente de trabajo para los habitantes de Cerro Castillo y Puyuhuapi. Es así como muchos de ellos, encuentran en lodges, termas o parques naturales, su principal fuente de ingresos, pues sus modos de vida campesinos no logran hacerse espacio dentro del mercado global.

Todo lo anterior nos invita a observar de manera crítica las formas aparentemente altruistas que toma el modelo económico, como lo es esta versión verde del capitalismo, ante el que nos preguntamos: ¿Qué intereses hay involucrados? ¿A quiénes está favoreciendo? ¿A precio de qué?

Para finalizar nuestra tarea de conocer los elementos que tensionan la relación de los habitantes locales con el bosque nativo en la actualidad, nos resta sólo adentrarnos en las normativas que rigen su uso.

\subsection{Normativas de uso del bosque}

Los bosques nativos en Aysén, se rigen bajo la Ley N²0.283 (2008) Sobre Recuperación del Bosque Nativo y Fomento Forestal, que está orientada a la conservación de los bosques nativos de Chile, y que rige todas las políticas de su cuidado y conservación (AIFBN 2011).

En Aysén, las actividades vinculadas al bosque están normadas con los planes de manejo (P.M) que especifica esta ley, y que regulan la extracción y utilización de todo tipo de leña y madera, además de la tenencia de animales, quemas y raleos. Los dueños de campo deben tener P.M para intervenir el bosque, y a la vez todos quienes transporten leña o madera deben contar con "guías de tránsito" que atestigüen que la madera que se transporta corresponde a predios que fueron trabajados con P.M.

Esta normatividad hace que la mayoría de las personas que trabajan en/con el monte de 
Puyuhuapi y Cerro Castillo queden al margen de lo legal, pues es un modelo que además de ser sumamente burocrático, no responde a la realidad de los pequeños campesinos de la región, o al menos de las localidades en donde se trabajó, pues la mayoría de ellos, como vimos, no son propietarios, han vendido sus tierras, 0 éstas se encuentran divididas entre muchos herederos a los que es difícil reunir y aunar en intereses para sacar un P.M . Lo anterior, se materializa en multas:

Una vez no teníamos leña, fuimos a buscar a la orilla y el (...) nos acusó a los carabineros y nos sacaron una multa que tuvimos que pagar. Mi ex marido le dijo al carabinero: "yo no puedo dejar a mis hijos morir de frío" (Flor, Puyuhuapi).

Una idea reiterada entre los habitantes locales respecto a este tema, es que "los que hacen las legislaciones no tienen idea como vive el campesino acá" (Antonio, Cerro Castillo). Estas ideas hacen alusión a que las normativas no consideran la realidad material y cultural de los habitantes del lugar, enjuiciando sus prácticas sin tomar en cuenta sus necesidades.

\section{Circuitos mercantiles y bosque nativo}

Como hemos ido revisando, existe un complejo entramado de relaciones entre las características medioambientales de Aysén, el turismo, el mercado de tierras y las normativas respecto al uso del bosque, estando todas estas dimensiones permeadas por el paradigma ecologista. Pero, ¿fue siempre así?

Los bosques de Aysén no han sido siempre valorados de este "verde" modo, como nos damos cuenta si miramos brevemente hacia el pasado.
Desde la colonización de la región hasta la actualidad, los bosques han tomado distintos valores para el Estado y el mercado, según el modelo de desarrollo que recae sobre Aysén en cada período.

Estas valorizaciones no son neutras ni para nada naturales, sino más bien responden a los intereses tanto de quienes piensan administrativamente la región (y la nación), como de quienes detentan los capitales que les permiten sacar provecho y lucrar con ellos.

Para comprender de modo general los circuitos de valor por los que ha transitado el bosque en Aysén, los ordenaremos en tres momentos.

En el primero de ellos, durante los siglos XVIII-XIX, se desarrolló una fuerte explotación de madera, principalmente de Ciprés de las Guaitecas y Alerce (Otero 2006; Martinic 2005), lo que implicó la quema de miles de hectáreas de bosques para obtener estas especies que se hallaban en medio de las selvas (Torrejón et al. 2013).

Luego de esta etapa, los bosques cambian de valor, dejando de ser cotizados y pasando a ser una molestia para los procesos de colonización de la región que se desarrollaron desde principios del siglo XX.

Durante el proceso de colonización de Aysén impulsado por el Estado, el "despeje" o "apertura" de los campos fue casi una exigencia para los colonos-campesinos, quienes no teniendo en esos tiempos otras herramientas ni medios, veían en el uso del fuego la mejor alternativa para desarrollar las labores agrícolas y la crianza de animales, y de ese modo poder cumplir con los requisitos que les exigían para 
acceder a sus títulos de propiedad (Martinic 2005). De forma paralela a este proceso conocido como "colonización espontánea", se utilizó el sistema de concesiones de tierra, con el objetivo de atraer a grandes compañías extranjeras que llevaran a cabo el proyecto ganadero que se tenía para la región. Un ejemplo es la compañía pastoril Sociedad Industrial y Comercial del Aysén (S.I.A) que sólo entre 1920 y 1940 quemó cerca de 2.800.000 hectáreas de bosque en la provincia de Aysén para la ejecución de sus labores (Veblen 1996 Cit. en Otero 2006: 105).

Lo anterior evidencia que, durante este segundo período, el bosque fue concebido como un estorbo para el asentamiento de los nuevos colonos y de las grandes empresas ganaderas.

El tercer momento que definimos en esta trayectoria de valores por la que transitan los bosques de Aysén, podemos rastrearlo desde la década de los 90' hasta la actualidad. Durante este período, los bosques adquieren valor por sus características medioambientales (Nuñez et al. 2014).

Bajo un paradigma de economía globalizada, a partir de 1980, Chile abre sus puertas a la inversión extranjera, dinámica que presiona los recursos naturales, lo que se hace visible en el alto número de empresas transnacionales involucradas en su explotación (Vallejos 2005). La región de Aysén entra en esta dinámica de mercantilización de la naturaleza, pero no a través de la explotación de recursos, sino en nombre de la conservación, lo que puede ser entendido bajo lo que Fairhead et al denominan "green grabbing" (2012: 238). Con este concepto los autores hacen alusión a la apropiación, privatización, individualización o alienación de ciertas piezas del medio ambiente, en nombre de la sustentabilidad o valores "verdes". En nuestro caso de estudio, lo anterior se materializa en el turismo y mercado de tierras, ambos asociados a las características medioambientales de Aysén.

De esta manera, si en Aysén, para comienzos del siglo $X X$, lo que propendía la riqueza de las empresas y el desarrollo del país era la industria ganadera -para lo que era necesario destruir los bosques-; lo que hoy genera ganancias es el mercado de lo verde, lo ecológico, lo sustentable, para lo que es necesario mantenerlos intactos. Esto es posible mediante el manejo de los espacios naturales en áreas protegidas $u$ otros dispositivos turísticos cerrados, lúdicos y sacralizados, que como señala Santamarina (2009), Ilevan implícita la separación naturaleza/ cultura al situar a la naturaleza como un dominio externo (sin seres humanos, pero creados por y para seres humanos), que se delimita y norma, dando lugar a esta particular mercantilización de la naturaleza a través del ocio y el consumo. Todo lo que hemos ido problematizando, hace visible la existencia de una pluralidad de intereses y valores sobre el bosque y sus recursos, los que se encuentran en conflicto. El Estado y las grandes empresas que han intervenido y gestionado a nivel global el uso de los bosques en la región, siempre les han dado un valor mercantil: primero asociado a las exportaciones de madera, luego a las empresas ganaderas, y hoy, que el mercado global valora los atributos "verdes" de Aysén, se lucra con ellos a partir de la conservación, el turismo y el mercado de tierras.

Por otro lado, los bosques dentro de las comunidades locales no se valoran en formato de "parques" intocables; pues justamente el valor que el monte tiene para las comunidades 
es que les brinda sustento y sentido de vida, como valores que en estos momentos son ajenos al mercado.

A pesar de que existen estas visiones múltiples, el paradigma ecologista del culto a lo silvestre, de la mano del mercado capitalista-verde y del Estado, imponen sus valores como los únicos, los correctos, los mejores, desconociendo este convivir de distintas percepciones, valoraciones y apropiaciones de lo natural.

Sumado a ello, las políticas conservacionistas se asientan, como advierte Santamarina (2009), no sólo en la distinción naturaleza/cultura, sino también en la distinción conocimiento científico/ conocimiento común, donde los conocimientos técnico-científicos que funcionan como soporte de las políticas de conservación, desplazan a los conocimientos locales.

Así es como, por ejemplo, los P.M en la práctica funcionan más como un dispositivo punitivo, que como un modelo que asegure la reproducción del bosque y de las economías campesinas. Estas pautas impuestas tienen como trasfondo el validar un modo único de cuidar los bosques, modo que se posiciona por sobre los modelos campesinos, buscando traspasarles conocimientos del medioambiente y normar sus maneras de relacionarse con la naturaleza.

Si bien estas normativas institucionales de uso del bosque nacen -suponemos- con la intención de recuperar el daño hecho en el pasado y con el fin de asegurar la reproducción y vida de los bosques, incluyendo a quienes lo trabajan, vale preguntarse hasta qué punto toman en cuenta las necesidades, valores, conocimientos y usos locales del entorno en pos de ese objetivo, en lugar de marginarlos del proceso y, en ciertas ocasiones, criminalizarlos.

Lo anterior ha sido trabajado por varios autores que según indica Santamarina (2009) han logrado dar cuenta cómo las normativas que regulan el uso de los recursos, reifican los dominios natural y cultural como independientes, dando origen a prescripciones y prohibiciones impuestas que redefinen los territorios, y que provocan expropiaciones, apropiaciones y reapropiaciones en ellos, borrando los usos y la historia local. A esto, Leff le llama la "colonización del conocimiento" (2014: 163), y lo define como el principal dispositivo de poder y dominio cultural aplicado para la apropiación de la naturaleza, desde la conquista de los pueblos originarios y sus territorios, hasta las estrategias actuales de la geopolítica del desarrollo sostenible.

\section{Lo prohibido y ajeno}

Al analizar el vínculo de los habitantes locales de Puyuhuapi y Cerro Castillo con el monte en el contexto neoliberal, nos damos cuenta que se encuentran enfrentados a una serie de dificultades para llevar a cabo sus prácticas del bosque. Esto se debe, por una parte, a que el acceso a las materias primas se encuentra restringido, pues los bosques de donde las obtienen son propiedad de externos que no permiten el ingreso a sus campos, o son parte de áreas protegidas del SNASPE (Sistema Nacional de Áreas Silvestres Protegidas del Estado) en las que tampoco pueden desarrollar sus actividades. Así mismo, los P.M que controlan cualquier actividad que se desarrolle en los bosques, cursando multas y castigos en caso del no cumplimiento de las normas, constituyen 
también una amenaza y una dificultad para el desarrollo de las prácticas locales.

Esto nos lleva a problematizar el hecho de que las prácticas vinculadas al bosque nativo en Puyuhuapi y Cerro Castillo pasen a ser bajo el contexto neoliberal criminalizadas y restringidas, lo que hace que el bosque se presente para los actores locales como prohibido y ajeno.

A la vez cuando relacionamos estos dos aspectos (lo ajeno en cuanto a la propiedad y lo prohibido en cuanto a la legalidad/ ilegalidad de las prácticas), vemos que el tipo de propiedad en donde se desarrollan las prácticas está directamente relacionado con la legalidad de éstas, en tanto el mayor número de prácticas ilegales se constituyen como tales pues se desarrollan en campos ajenos sin la "autorización" de sus dueños. De esta manera, lo ajeno lo hace ser prohibido a la vez que lo prohibido -dada la normatividad institucional y la moral ecológica- alejan al bosque de sus comunidades, tornándolo también ajeno. De esta forma, aun cuando las actividades se realicen en campos propios o de familiares, siguen siendo en su mayoría "ilegales" o "prohibidas" pues infringen las normas institucionales de uso del P.M, pese a ser prácticas fundamentales para sus vidas: "Está bien el cuidado de la naturaleza, pero cuando una tiene necesidad, no le queda otra" (Luz, Puyuhuapi).

Esta cita de Luz, nos recuerda íntimamente el relato del pescador en el clásico libro de Hemingway "El viejo y el mar", el que nos invita a reflexionar respecto a cómo la depredación, explotación o utilización de los recursos a nivel local, debe ser analizada como un fenómeno siempre complejo, en donde el observador o el juez no logra librarse del contexto, época y cultura de donde nace su mirada, y de ese modo, hace de estas prácticas algo difícil de juzgar:

No lo entiendo y no estoy seguro de creer en el pecado. Quizá haya sido un pecado matar al pez. Supongo que sí, aunque lo hice para vivir y dar de comer a mucha gente. Pero entonces todo es pecado. No pienses en el pecado. Es demasiado tarde para eso y hay gente a la que se paga por hacerlo. Deja que ellos piensen en el pecado. Tú naciste para ser pescador y el pez nació para ser pez (...) Además -pensó-, todo mata a lo demás en cierto modo. El pescar me mata a mi exactamente igual que me da la vida (Hemingway 1952: 120-121).

Leff (2014) parece ir en la misma línea al postular que la diversidad cultural implica que no existan bases para creer en una conciencia ecológica trans-individual y transcultural unificada de la especie humana. Debido a los distintos contextos geográficos, culturales, económicos, sociales y ambientales, aun cuando sean problemas aparentemente comunes, se perciben de distinto modo según las distintas visiones, y también dan origen a diferenciadas acciones y estrategias de poder.

Esta reflexión nos permite des-idealizar la imagen que tenemos de los habitantes del lugar al menos en dos sentidos. Primero, deshaciéndonos de la ya añeja imagen del nativo "buen salvaje" que vive o debiera vivir en una completa armonía con su medio, sin explotar ni abusar de sus recursos. Ya vimos que, en nuestro caso de estudio, hacen y necesitan hacer un uso constante de los recursos del monte, así como los seres humanos hemos hecho uso toda la historia de los recursos naturales para nuestra sobrevivencia.

Romper esa idealización debe hacerse con cuidado de no caer en la contraria: que los habitantes locales son los culpables de la 
degradación ambiental y la destrucción del bosque, pues como vimos, sus mayores destructores han sido siempre los grandes capitales de la mano del Estado, quienes han impulsado todos los procesos que generaron en los bosques de Aysén los mayores daños, como lo fueron la sobreexplotación maderera y las grandes quemas durante su colonización.

\section{Bosquejos del monte para concluir y abrir.}

Al hacer el ejercicio de observar esta postal ficticia de los bosques de Aysén desidealizándola y considerando ya no solo su bella imagen natural-neutral sino sus distintas aristas, con una multiplicidad de dimensiones, actores, entradas y conflictos, nos damos cuenta que efectivamente en los territorios se expresan disputas de poder, en las que los paisajes van re-significándose y cambiando de valor. En nuestro caso de estudio, la élite económica y política lo hace a su favor y en la actualidad esto se materializa en políticas de mercantilización de la naturaleza en nombre del ecologismo y la conservación, que en las localidades provocan que el bosque aparezca como prohibido y ajeno, poniendo en riesgo la reproducción de la vida material y cultural de sus comunidades.

Sin embargo, en nuestros zooms a esta imagen ficticia, y a partir de nuestro acercamiento etnográfico a este fenómeno social, constatamos que aún ante estos complejos y adversos escenarios, las prácticas locales se adaptan, tomando nuevas formas y buscando entre las rendijas de este sistema cómo seguir con vida. Así, mientras haya bosque habrá leña, correrán los mates, tomarán color las medias de lana, los malestares y embrujos tendrán cura, las fiestas chicha, los animales corrales, las tortas fritas dulces de fruta, los canastos boqui y los jardines flores.

De esta manera, el ensamblaje monte-habitantes locales se va constituyendo como una fuerza difícil de alienar, pues está en el corazón de las comunidades, corporeizada en sus habitantes locales con los que va reactivándose cotidianamente. En ese sentido lo entendemos como un movimiento más que de resistencia, de re-existencia de los pueblos y la naturaleza, en la línea de Leff, quien lo plantea como:

\section{las luchas por la afirmación de seres culturales que enfrentan las estrategias de dominación y apropiación promovidas e impuestas por la globalización económica (2014: 181).}

En cuanto al trabajo que nos queda por hacer, consideramos necesario que investigaciones como éstas sean capaces de salirse de su mirada netamente local, lo que es un desafío no solo para este estudio sino para la antropología en general. En ese sentido, recogemos el afán de la ecología política por entender los conflictos socioambientales dentro de marcos amplios, analizando agudamente la interacción entre lo local y lo global.

Por otra parte, destacamos el rol de la etnografía, que a través de este tipo de trabajos demuestra, como lo plantea Santamarina (2009), la necesidad de convertir a la antropología en una herramienta para abrir diálogos hacia una gobernanza medioambiental basada en la participación y la diversidad, frente a la exclusión y la homogeneización. 


\section{Bibliografía}

AIFBN. 2011. Hacia un nuevo modelo forestal. Disponible en: http://www.nuevomodeloforestal.cl/Hacia_un_Nuevo_Modelo_ Forestal_AIFBN.pdf (consultado en julio 2015).

CODEFF. 2005. Proyecto Fortalecimiento para Aysén Reserva de Vida. Foros taller Aysén Reserva de Vida 1997. Aysén: Fundación AVINA.

Descola, P. 2011. "Más allá de la Naturaleza y la Cultura". Cultura y Naturaleza. Aproximaciones a propósito del Bicentenario de la independencia de Colombia. Montenegro, L. (Ed). Bogotá: Jardín Botánico José Celestino Mutis. 75-97.

Elliot, P. 2006. "Ecología política como etnografía: Um guía teórico e metodológico". Horizontes Antropológicos, Porto Alegre (25): 85-103.

Fairhead, J., Leach, M., \& Scoones, I. 2012. "Green Grabbing: a new appropriation of nature?". The Journal of Peasant Studies (2): 237-261.

GORE. 2009. Estrategia Regional de Desarrollo. Coyhaique. Disponible en: http://www.subdere.gov.cl/sites/default/files/ documentos/articles-82944_archivo_fuente.pdf (consultado en julio 2015). Planeta.

Hemingway, E. 1952. El viejo y el mar. Barcelona: Editorial

INFOR. 2012. Diagnóstico y propuestas para la industria del aserrío en la región de Aysén. Disponible en: http://biblioteca. infor.cl/DataFiles/30796.pdf (consultado en agosto 2014).

Leff, E. 2014. La apuesta por la vida. Imaginación sociológica e imaginarios sociales en los territorios ambientales del sur. México: Siglo XXI Editores.

Ludwig, L. 2013. Puyuhuapi. Curanto y Kuchen. Historia Oral de un pueblo de Aysén. Valdivia: Ediciones Kultrún.

Martínez-Alier, J. 2014. El ecologismo de los pobres. Conflictos ambientales y lenguajes de valoración. Santiago: Editorial Quimantú.

Martinic, M. 2005. De la Trapananda al Aysén: una mirada reflexiva sobre el acontecer de la Región de Aysén. Santiago: Editorial Pehuén.

Nuñez, A., Aliste, E., \& Bello, Á. 2014. "El discurso del desarrollo en Patagonia-Aysén: La conservación y la protección de la naturaleza como dispositivos de una renovada colonización. Chile, siglos XX-XXI". XIII Coloquio Internacional de Geocrítica: EI control del espacio y los espacios de control. Barcelona, 5-10 de mayo de 2014.

Nuñez, A., Aliste, E., Bello, A. 2016. "Patagonia-Aisén, Reserva de Vida: El discurso de la naturaleza como nueva utopía capitalista. Chile, Siglo XXI. XIV". Coloquio Internacional de Geocrítica: Las utopías y la construcción de la sociedad del futuro. Barcelona, 2-7 de mayo de 2016.

Otero, L. 2006. La huella del fuego. Historia de los bosques nativos. Poblamiento y cambios en el paisaje del sur de Chile. Santiago: Editorial Pehuén.

Rodríguez, J., Medina, P., Reyes, S. 2014. “Territorio, paisaje y marketing global. Imaginarios en la construcción de la Patagonia como marca". Magallania 42(2): 109-123

Romero, D. 2017. "El cambio de la propiedad de la tierra en el Valle Exploradores: el re-escalamiento de los espacios locales y la construcción de una nueva idea de la cordillera patagónica occidental (1960-2014)". Imaginarios geográficos, prácticas y discursos de frontera. Aisén-Patagonia desde el texto de la nación. Nuñez, A. et al. (Eds.). Santiago: LOM. 283-302.

Santamarina, B. 2008. "Antropología y Medio Ambiente: Revisión de una tradición y nuevas perspectivas de análisis en la problemática Ecológica". Revista de Antropología Iberoamericana (3):144-184.

Santamarina, B. 2009. "De parques y naturalezas. Enunciados, cimientos y dispositivos". Revista de dialectología y tradiciones populares (64): 297-324.

SERNATUR. 2015. Región de Aysén. Disponible en: http:// www.sernatur.cl/region-de-aysen/?lcp_page0=3\#lcp_instance_0 (consultado en julio 2015).

Torrejón, F., Bizama, G., Araneda, A., Aguayo, M., Bertrand, S. \& Urrutia, R. 2013. "Descifrando la historia ambiental de los archipiélagos de Aysén: El influjo colonial y la explotación económica-mercantil republicana (Siglos XVI-XIX)". Magallania (41): 29-52.

Ulloa, A. 2001. "Transformaciones en las investigaciones antropológicas sobre naturaleza, ecología, y medio ambiente". Revista colombiana de antropología (37): 188-232.

Vallejos, A. 2005. "Los conflictos ambientales en una sociedad mundializada. Algunos antecedentes y consideraciones para Chile". Revista LIDER (13): 193-214. 
